\title{
Die Consuetudines
}

Liebe Leserinnen, liebe Leser,

Datenschutz ist eine Verschränkung von Datenverarbeitung und dem Bedürfnis nach Sicherheit. Die Datenverarbeitung regt das Bedürfnis an; die maßgeblichen Ursachen des Datenschutzes liegen aber in der menschlichen Psyche. Sie fühlt sich durch anonyme Mächte bedroht, die ihren "geheimen Namen“ in Erfahrung bringen können. Diese Betroffenheit ist menschlich und zeitlos. Das zeigt die Geschichte. Sie zeigt auch, dass sich die Art der Betroffenheit mit der Zeit verändert. Sie prägt sich heute anders aus als früher. Etwa vor zweihundert Jahren. Da schrieb Adelbert von Chamisso das Märchen von Peter Schlehmihl, der seinen Schatten an den Teufel verkauft hatte. Der Dichter schrieb damit zu einem Thema, das - wie der Datenschutz - eben die Angst des Individuums vor dem Ungewissen betrifft.

Das Mittelalter hingegen befasste sich nicht mit dem Individuum. Seine Gesellschaft war ständisch gegliedert; die Menschen Gemeinschaften zugehörig, in die sie hereingeboren waren und die innen Heimat gaben. Daneben waren sie örtlich oder beruflich in geschlossenen Gruppen, wie Zünften etc., organisiert. Deren Mitglieder erkannten einander an gemeinsamer exklusiver Information, also an gemeinschaftsbezogenen Daten, die den personenbezogenen Daten von heute vergleichbar sind, nur dass sie nicht das Individuum sondern die Gemeinschaft betrafen.

Im hohen Mittelalter war da z.B. der Templerorden. Er wurde 1118 anlässlich des 1. Kreuzzugs von französischen Rittern gegründet. Seinen Sitz hatte er auf dem Tempelberg von Jerusalem; daher der Name. Er stellte sich die Aufgabe, die christlichen Pilger zu beschützen, die Wege nach Jerusalem sicher zu halten. Dem entsprechend beteiligte er sich an den sonstigen militärischen Aktivitäten der Christen. Er gab sich Statuten, nach der Regel des heiligen Benedikts und von der Kirche genehmigt, und entwickelte dazu Ausführungsbestimmungen, die Consuetudines/Gepflogenheiten, die aber - im Gegensatz zu den Statuten - geheim waren.

Der Orden wurde von Bernhard von Clairvaux, dem PR-Motor des ersten Kreuzzugs, gefördert und erhielt viel Zulauf und Schenkungen. Die Ritter, die ihm beitraten, brachten ihm weiteren Besitz ein. Sein Vermögen wuchs. Er verlegte sich darauf, es zu verwalten und zu mehren. Seine Besitzungen, Komtureien und Burgen, verteilten sich über das Heilige Land hinaus auf ganz Europa. So kamen die Templer zu viel Geld und ins Geschäft. Sie entwickelten sogar - im heutigen Sinne - Finanzprodukte; der Orden wurde zum potentesten Kreditinstitut seiner Zeit. Könige und Fürsten waren auf ihn angewiesen und bei ihm verschuldet. Er wurde zum Ziel von Begehrlichkeiten. Er stand überdies in schlechtem Ruf; man verdächtigte die Ritter der Sodomie (gemeint war gleichgeschlechtlicher Verkehr). 1307 machte Philipp IV, König von Frankreich, dem Orden ein minutiös geplantes Ende. Er erließ einen Haftbefehl gegen ausnahmslos alle Templer; sie wurden zum Großteil Razzia-artig gefangen gesetzt und der Häresie angeklagt, das Vermögen beschlagnahmt. Die Inquisition wurde auf den Orden angesetzt. Der darauf folgende Prozess geriet in die Machtspiele zwischen König und Papst. Er zog sich in die Länge und führte letztlich zur Auflösung des Ordens, nicht zu seiner Verurteilung. Aber seine militärische Potenz war vernichtet; sein Besitz der Kirche verblieben. Der skandalöseste Punkt der Anklage war „Sodomie“. Diesbezüglich spielten die Consuetudines eine wichtige Rolle. Sie waren zum Schrecken der Templer-Verwaltung den Leuten des Königs in die Hände gefallen. Der setzte sie im Prozess ein. Er konnte offensichtlich - das lässt obiger Schrecken vermuten - mit ihnen seine Anklage erhärten. Die Consuetudines waren also - im heutigen Sinne - höchst sensitive, auf die juristische Person bezogene Daten.

Ich meine, liebe Leserinnen und Leser: Dass sie im heutigen Sinne schutzbedürftig sind, wäre auch den Menschen des Mittelalters plausibel gewesen. Wer aber weiß, ob sie das gegebenenfalls auch für das Individuum und unseren Datenschutz empfunden hätten.

Mit freundlichen Grüßen, Ihr

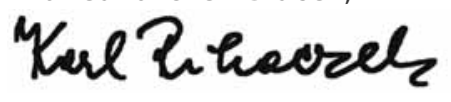

